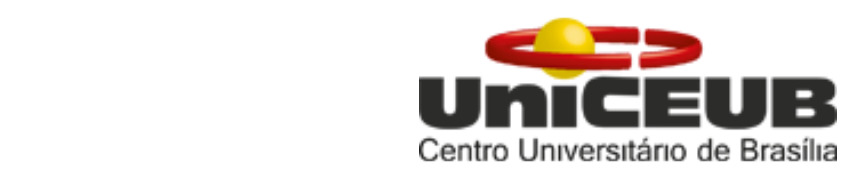

CENTRO UNIVERSITÁRIO DE BRASÍLIA - UNICEUB PROGRAMA DE INICIAÇÃO CIENTÍFICA

STÉPHANIE BACCIN FLECK SILVA

VALIDAÇÃO DE INSTRUMENTOS SOBRE CRENÇAS E HÁBITOS EM RELAÇÃO AO TABAGISMO

BRASÍLIA 


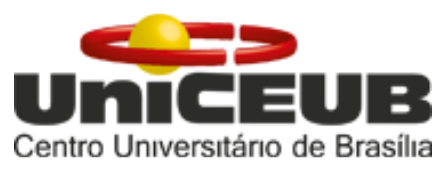

STÉPHANIE BACCIN FLECK SILVA

\section{VALIDAÇÃO DE INSTRUMENTOS SOBRE CRENÇAS E HÁBITOS EM RELAÇÃO AO TABAGISMO}

Relatório final de pesquisa de Iniciação Científica apresentado à Assessoria de Pós-Graduação e Pesquisa.

Orientação: Marina Kohlsdorf

\section{BRASÍLIA}




\section{Resumo}

No Brasil existem aproximadamente 18 milhões de fumantes, sendo os jovens adultos e adolescentes, principalmente estudantes, vulneráveis ao vício. Considerando que o hábito tabagista desencadeia uma série de doenças e complicações de saúde, deve ser alvo de estudos e programas de prevenção. Nesse contexto, o objetivo do estudo é validar instrumentos sobre crenças e hábitos em relação ao tabagismo. Participaram da pesquisa 30 estudantes universitários, sendo $50 \%$ homens e $50 \%$ mulheres, $63,33 \%$ entre 22 e 25 anos, $60 \%$ entre o $7^{\circ}$ e o $10^{\circ}$ semestre, $66,66 \%$ iniciaram o hábito entre os 14 e 17 anos. Os participantes responderam um questionário contendo 80 itens para avaliação entre 1 (discordo totalmente) e 5 (concordo totalmente), além de 3 questões de resposta aberta. Foram realizadas análises descritivas de média, desvio padrão e número, que permitiram concluir a forte relação do hábito dos universitários com a socialização e o consumo de bebidas alcoólicas, e também como o hábito não aparenta prejudicar as atividades desempenhadas pelos participantes.

\section{Palavras-Chave: Instrumento. Tabagismo. Universitários.}




\section{Introdução}

Segundo a Organização Mundial da Saúde (OMS), o Brasil ocupa o oitavo lugar no ranking de número absoluto de fumantes, cerca de 11 milhões de homens e 7 milhões de mulheres. O tabagismo é a maior causa isolada de morte evitável, passível de prevenção, no mundo, e uma das principais no Brasil (Instituto Nacional de Câncer - INCA, 2011; Organização Mundial de Saúde - OMS, 2008, citados por Guerra et al., 2017). Esse hábito desencadeia uma série de doenças crônicas, como diferentes tipos de câncer, doença pulmonar obstrutiva crônica (DPOC), doença coronariana, hipertensão arterial e acidente vascular encefálico (Barreto, 2002; Danaei et al., 2005; Instituto Nacional de Câncer - INCA, 2011; citados por Guerra et al., 2017). Além dos impactos na saúde dos usuários e nas suas famílias, esse hábito resulta em um grande gasto governamental, contando a necessidade de assistência a saúde e da falta de produtividade e perda de renda (Kroeff \& Mengue, 2002-2003, citado por Guerra et al., 2017).

Os adolescente e jovens adultos aparecem como grupos de grande vulnerabilidade diante do tabagismo, principalmente os estudantes (Vargas et al., 2017). A Organização Mundial de Saúde (OMS, 2017) estimou as taxas de prevalência do uso de tabaco em 31,1\% para homens e 6,8\% para mulheres, enquanto no Brasil, essas taxas são, respectivamente, $21 \%$ e $12 \%$ (Vargas et al., 2017).

O tabagismo só passou a ser definido como doença na década de noventa, sendo assim a definição do que é ser fumante ainda não está clara. As diferentes concepções podem causar divergências em estudos sobre o assunto e inclusive em intervenções terapêuticas, considerando que um grupo de fumantes que fuma um cigarro por semana vai aderir ao programa de forma diferente que fumantes que fumam um maço de cigarros por dia (Barsosa et al., 2014). 
Há uma convergência nos critérios diagnósticos apresentados pelo CID-10 e pelo DSM-IV no que diz respeito a definição e classificação da dependência, mas esses critérios muitas vezes não são utilizados pelos programas de tratamento ou pelas pesquisas sobre o tema (American Psychiatric Association,2008; WHO, 1992, citados por Barbosa et al., 2014). A dependência química é vista como uma enfermidade incurável e progressiva, que pode estar estacionada pela abstinência. É o conjunto de fenômenos comportamentais, cognitivos e fisiológicos que se desenvolvem após repetido consumo de uma substância psicoativa, sendo que o diagnóstico apenas pode ser feito se três ou mais critérios tenham sido preenchidos por um determinado tempo durante o último ano (CID-10; DSM-IV-TR, citados porBarbosa et al., 2014).

Apesar dessas definições nem todo fumante pode ser classificado como dependente químico, logo, os estudos têm considerado os participantes fumantes ou não de acordo com critérios estabelecidos pelos pesquisadores, alguns utilizando frequência de consumo, outros resultados em escalas de tabagismo, não existindo um padrão de classificação (Barsosa et al., 2014).

O tabagismo é responsável pela morte de 6 milhões de pessoas por ano, principalmente por doenças crônicas não transmissíveis, sendo assim um grande problema de saúde pública (Arrazola et al., 2013, Barreto et al 2014, citados por Vargas et al., 2017). Considerando esse contexto a OMS elaborou diretrizes visando auxiliar os países no controle do uso de tabaco, tais medidas são denominadas MPOWER - Monitoring tobacco use (Monitorar o uso do tabaco); Protecting people from tobacco smoke (Proteger as pessoas da fumaça do tabaco); Offering help to quit tobacco use (Oferecer ajuda para abandonar o uso do tabaco); Warning about the dangers of tobacco (Alertar sobre os perigos do tabaco); Enforcing bans on tobacco advertising (Fazer cumprir a proibição da propaganda do tabaco) e Raising taxes on tobacco products (Aumentar os impostos dos produtos do tabaco) (World 
Health Organization, 2013, citado por Martins et al., 2017).

De acordo com as recomendações da OMS, a Lei ${ }^{\circ} 10.167,10$ foi criada no dia 27 de dezembro de 2000, proibindo a publicidade direta do tabaco, ocorreu uma grande queda do consumo desse produto. Além disso, o governo procura realizar ações de controle e prevenção ao tabagismo, como informar a população sobre os malefícios e atribuir as industrias do tabaco ações socialmente responsáveis (Instituto Nacional de Câncer - INCA, 2014, citado por guerra et al., 2017).

Martins e companheiros (2017) realizaram um estudo com alunos do terceiro ano de medicina da Faculdade de Medicina da Universidade de São Paulo e constataram que o consumo de tabaco abrange 5,23\% da amostra, mas mais de $40 \%$ já haviam consumido narguilé com tabaco. É necessário que sejam criadas campanhas educativas sobre o uso desse tipo de produto, considerando que existe uma crença entre os jovens que o consumo de tabaco no narguilé é menos prejudicial que fumar cigarros (Global Tobacco Surveillance System Collaborating Group, 2005, citado por Martins et al., 2017).

Apesar das ações que procuram diminuir o consumo de tabaco, os universitários apresentam um público promissor, com capacidade de manter e até expandir o mercado, já que atualmente é o público que mais consome cigarros industrializados (Rull et al., 2011; Ministério da Saúde, 2014, citados por Guerra et al., 2017). Muitas vezes o consumo de tabaco começa antes da universidade, uma idade na qual os indivíduos possuem dificuldade em associar os malefícios à saúde, mostrando a necessidade de ações preventivas para essa população mais jovem (Ramis et al., 2012, citado por Guerra et al., 2017).

A adolescência, fase da vida que alguns autores têm prolongado dos 18 anos (Eisenstein, 2005, citado por Costa et al., 2017), é um período de adaptação à novos meios, quando novos laços de amizade são criados, ocorrem mudanças no corpo, na mente, nos relacionamentos, na visão do mundo, e assim acabam experimentando coisas novas, muitas 
vezes por curiosidade (Almeida, 2011; Costa et al., 2017). Como é um período da vida associado à vulnerabilidade, pode favorecer a incidência de uso de substância psicoativas. Associado a esse consumo estão algumas crenças que procuram justificar o consumo, valorizando o prazer imediato e diminuindo a importância das consequências à saúde dos usuários (Costa et al., 2017).

O comportamento de fumar de jovens e estudantes é comumente descrito como fumar socialmente, envolvendo diversos fatores e definições, como fumar apenas em bares e clubes noturnos, fumar na presença de outros fumantes, etc (Barsosa et al., 2014). Essa forma de considerar tais jovens fumantes sociais pode fazer com que eles não se identifiquem como fumantes e desvalorizem as consequências de seus atos à saúde (Levinson et al., citados por Barsosa et al., 2014).

Uma substância é considerada psicoativa quando modifica o funcionamento mental, por meio da interferência nos mecanismos bioquímicos, podendo causar efeito de excitação, sedação ou perturbação (Costa et al., 2017). Estudos do mundo inteiro têm apresentado que as substâncias de uso mais comum são o álcool, tabaco, maconha e estimulantes, sendo os solventes mais utilizados por adolescentes mais jovens (Almeida, 2004, 2011). Dependendo da substância e do consumo associado, a saúde do consumidor pode ser prejudicada, podendo o uso ser classificado entre seis etapas: primeiro contato, experimentação ocasional, consumo regular, consumo excessivo, dependência e quadro aditivo, sendo que os riscos à saúde tendem a aumentar de acordo com a fase (Patrício, 2002, 2006, citado por Costa et al., 2017).

O uso de drogas sempre esteve presente na humanidade, variando a motivação, como o uso nos cultos religiosos ou por recreação. Na modernidade novas formas e motivações aparecem, sendo o álcool provavelmente a substância mais utilizada em todo mundo, e o uso considerado aceitável dependendo da quantidade e frequência. Além disso, o consumo de álcool muitas vezes acarreta o uso de substâncias de risco, ou mais prejudiciais à saúde, assim 
como o consumo de cigarros. De acordo com os resultados encontrados por Almeida (2011), tabaco aparece em primeiro lugar no que diz respeito a associação do uso de mais um tipo de droga, com 35\% dos usuários, seguido pelo consumo de álcool (23\%) e da maconha (21\%).

Vargas e companheiros (2017), com o objetivo de estimar a prevalência e os determinantes do consumo de tabaco por estudantes, realizaram um estudo de corte transversal em estudantes de escolas públicas em um município no interior de Goiás, localizadas em áreas urbanas e rurais. Os participantes tinham idade igual ou superior a 10 anos, definido pela OMS como início da adolescência, e estavam devidamente matriculados no ensino fundamental e médio ou no curso de Educação de Jovens e Adultos. A amostra totalizou 701 estudantes, entrevistados pessoalmente, as variáveis de desfecho do estudo foram "consumo de tabaco pelo menos uma vez na vida" e "consumo regular de tabaco", definido pelo uso em um ou mais dias nos últimos 30 dias (Barreto et al., 2012, citado por Vargas et al., 2017).

Os resultados demonstram que a maioria da amostra apresentou dependência a nicotina, $74,5 \%$, sendo alta a prevalência do uso de tabaco e a vulnerabilidade dos estudantes no que diz respeito a esse comportamento. Algumas questões estão associadas a esse consumo: aumento de idade, sexo masculino, possuir pai ou mãe fumante. Estudantes sem religião apresentam maior prevalência de consumo regular de tabaco, sendo a crença religiosa considerada um fator protetor. O estudo encontrou associação relevante entre disfuncionalidade familiar e consumo de tabaco, a partir do instrumento Apgar (Vargas et al., 2017).

A partir do que foi abordado, o campo do tabagismo ainda é pouco abrangente para lidar com o pluralismo de definições e tipos de consumo. Essa riqueza que impede que haja uma definição de ser fumante deve ser utilizada para formulação de definições embasadas e consistentes de instrumentos validados de avaliação que deem conta da diversidade. Sendo 
assim é necessário que ocorram estudos aprofundados e a estruturação de programas de tratamento específicos visando maior sucesso no entendimento do tabagismo e auxílio na sua cessação (Barsosa et al., 2014).

Nesse contexto o objetivo do estudo é validar instrumentos sobre crenças e hábitos em relação ao tabagismo. Especificamente, pretende-se verificar quais são os hábitos que influenciam os jovens universitários a manter o tabagismo. 


\section{Método}

\section{Participantes}

Participaram da pesquisa 30 estudantes do Centro Universitário de Brasília (UniCEUB) que possuem atualmente hábito tabagista. O perfil dos participantes será apresentado na Tabela 1.

Tabela 1

Características dos participantes

\begin{tabular}{|c|c|c|}
\hline Características & $\mathrm{N}^{\mathrm{o}}$ & $\%$ \\
\hline \multicolumn{3}{|l|}{ Sexo } \\
\hline Masculino & 15 & 50 \\
\hline Feminino & 15 & 50 \\
\hline \multicolumn{3}{|l|}{ Idade } \\
\hline $18-21$ anos & 7 & 23,33 \\
\hline $22-25$ anos & 19 & 63,33 \\
\hline $26-30$ anos & 4 & 13,33 \\
\hline \multicolumn{3}{|l|}{ Semestre } \\
\hline $1^{\circ}-3^{o}$ & 6 & 20 \\
\hline $4^{\circ}-6^{o}$ & 6 & 20 \\
\hline $7^{\circ}-10^{\circ}$ & 18 & 60 \\
\hline \multicolumn{3}{|l|}{ Consumo de cigarros } \\
\hline Aos finais de semana & 11 & 36,66 \\
\hline $1-3$ & 13 & 43,33 \\
\hline $4-6$ & 4 & 13,33 \\
\hline 7 ou mais & 2 & 6,66 \\
\hline \multicolumn{3}{|l|}{ Religião } \\
\hline Não possui religião & 12 & 40 \\
\hline Católica & 12 & 40 \\
\hline Agnóstica & 2 & 6,66 \\
\hline Budista & 1 & 3,33 \\
\hline Cristã & 1 & 3,33 \\
\hline Espírita & 2 & 6,66 \\
\hline \multicolumn{3}{|l|}{ Renda } \\
\hline Até 3 mil & 13 & 43,33 \\
\hline 4 mil a 6 mil & 3 & 10 \\
\hline 7 mil ou mais & 4 & 13,33 \\
\hline \multicolumn{3}{|c|}{ Idade de início do hábito tabagista } \\
\hline $14-17$ anos & 20 & 66,66 \\
\hline $18-22$ anos & 10 & 33,33 \\
\hline \multicolumn{3}{|l|}{ Curso } \\
\hline Direito & 3 & 10 \\
\hline Publicidade & 5 & 16,66 \\
\hline Administração & 6 & 20 \\
\hline Engenharia Civil & 6 & 20 \\
\hline Psicologia & 6 & 20 \\
\hline Gestão Pública & 1 & 3,33 \\
\hline Letras & 1 & 3,33 \\
\hline Ciências Contábeis & 2 & 6,66 \\
\hline
\end{tabular}

A partir da Tabela 1 destaca-se que a amostra contou com o mesmo número de participantes do sexo masculino e do sexo feminino, 15 cada. Além disso, 63,33\% dos 
participantes possuem entre 22 e 25 anos, enquanto $66,66 \%$ iniciaram o hábito tabagista com menos de 18 , entre 14 e 17 . No que diz respeito ao consumo atual de cigarros, $43,33 \%$ dos participantes fumam entre 1 e 3 cigarros por dia e $36,66 \%$ fumam apenas aos finais de semana, normalmente associado ao consumo de bebidas alcoólicas.

Os cursos com mais participantes são Administração, Engenharia Civil e Psicologia, cada um com $20 \%$. Também é possível destacar que $60 \%$ da amostra encontra-se entre o $7^{\circ} \mathrm{e}$ o $10^{\circ}$ semestre, $43,33 \%$ possui até 3 mil reais de renda, $40 \%$ não possui religião e $40 \%$ são católicos.

Todos os participantes possuem ensino superior completo, não possuem outro curso de graduação e estão solteiros. Na amostra encontram-se 27 estudantes, 1 autônomo, 1 microempreendedor e 1 professor. Na maioria dos casos apenas o participante possui hábito tabagista em caso, apenas 3 residem com outros fumantes.

\section{Procedimentos}

O estudo foi submetido e aprovado pelo Comitê de Ética em Pesquisa (CEP). Os dados foram coletados de forma presencial no Centro Universitário de Brasília - UniCEUB. Alunos que estavam fumando nas instalações da instituição de ensino foram convidados a responder o questionário.

Inicialmente os respondentes foram instruídos a ler o Termo de Consentimento Livre e Esclarecido (TCLE), e então prosseguir ou não com a participação. O TCLE é um documento escrito de maneira resumida e com linguagem acessível que informa o sujeito sobre a pesquisa de maneira que possa tomar sua decisão em participar ou não, sem constrangimento. 


\section{Instrumentos}

Foi criado um intrumento envolvendo crenças sobre hábitos tabagistas, totalizando 80 sentenças que devem ser avaliados de acordo com a escala de 1 (discordo totalmente) a 5 (concordo totalmente). Além desses itens, o instrumento contempla perguntas de resposta aberta: "Por que razão começou a fumar?", "Já tentou interromper o hábito tabagista? Como foi a experiência?” e "Quando você fuma em ambiente comunitário, se preocupa ou chega a pensar se outras pessoas em volta estão incomodadas com o hábito?”.

No estudo também foi utilizado um questionário sociodemográfico abordando idade, sexo, curso, semestre, escolaridade, profissão, estado civil, se o participante possui outro curso de graduação, quantos cigarros fuma por dia, religião, renda, com quantos anos iniciou o hábito tabagista e quantas pessoas em casa fumam.

\section{Análise de Dados}

Os dados foram analisados no pacote estatístico SPSS (Statistical Package for Social Science) versão 23.0. Foram realizadas estatísticas descritivas (número, média e desvio padrão) para analisar a percepção dos participantes em relação ao seu hábito tabagista. 


\section{Resultados}

Inicialmente, na Tabela 2, serão apresentadas as estatísticas descritivas realizadas de acordo com as percepções dos participantes sobre as crenças em relação ao tabagismo.

Tabela 2

Crenças sobre o tabagismo com avaliações mais altas

\begin{tabular}{lc}
\hline Itens & Média (DP) \\
\hline 11. Consumir bebidas alcoólicas me deixa com vontade de fumar & $4,53(1,07)$ \\
7. Sinto vontade de fumar quando bebo & $4,40(1,10)$ \\
61. Parar de fumar melhoraria a minha saúde & $4,40(1,24)$ \\
62. Parar de fumar melhoraria minha respiração & $4,40(1,24)$ \\
64. Parar de fumar melhoraria meu desempenho nos esportes & $4,40(1,24)$ \\
63. Parar de fumar aumentaria meu fôlego & $4,33(1,24)$ \\
40. Apoio meus amigos a pararem de fumar & $4,10(1,26)$ \\
55. Costumo filar o cigarro dos meus amigos & $4,06(1,20)$ \\
1. Fumar me deixa mais calmo & $3,96(1,03)$ \\
31. Minha família gostaria que eu parasse de fumar & $3,93(1,48)$ \\
3. Fumar ajuda na minha socialização & $3,80(0,96)$ \\
2. Fumar alivia minha ansiedade & $3,60(1,40)$ \\
44. Comecei a fumar na adolescência & $3,60(1,79)$ \\
54. Costumo dividir um maço de cigarro com meus amigos & $3,60(1,47)$ \\
45. Comecei a fumar para me adaptar a um ciclo social & $3,59(1,10)$ \\
34. Meus médicos incentivam que eu pare de fumar & $3,56(1,47)$ \\
19. Não gosto do gosto que o cigarro deixa na minha boca & $3,53(1,27)$ \\
20. Não gosto do meu cheiro quando fumo & $3,46(1,63)$ \\
4. Fumar me aproxima dos meus amigos & $3,40(1,13)$ \\
14. Fumo quando estou ocioso & $3,40(1,45)$ \\
37. Quando meus amigos param de fumar, sinto que também consigo & $3,36(1,51)$ \\
57. Eu compro meu próprio maço de cigarro & $3,36(1,71)$ \\
60. Considero fumar um desperdício do meu dinheiro & $3,36(1,69)$ \\
66. Parar de fumar melhoraria meu hálito & $3,33(1,68)$ \\
77. Parar de fumar aumentaria meu stress & $3,33(1,49)$ \\
76. Parar de fumar melhoraria meu cheiro & $3,30(1,64)$ \\
80. Teria dificuldade em ver amigos fumando se parasse de fumar & $3,30(1,66)$ \\
67. Parar de fumar melhoraria meu paladar & $3,23(1,79)$ \\
65. Parar de fumar melhoraria minha situação financeira & $3,20(1,73)$ \\
78. Parar de fumar aumentaria meu nervosismos & $3,16(1,53)$ \\
53. Fumo quando estou sozinho & $3,10(1,58)$ \\
17. Fumar me mantém entretido & $3,03(1,40)$ \\
51. Fumo apenas quando estou com meus amigos & $3,03(1,54)$ \\
68. Parar de fumar aumentaria meu apetite & $3,03(1,80)$ \\
\hline & \\
\hline
\end{tabular}

De acordo com a Tabela 2 a sentença "Consumir bebidas alcoólicas me deixa com vontade de fumar" (média $=4,53 ; \mathrm{DP}=1,07$ ) foi avaliada de forma mais alta pelos participantes do que as outras sentenças, seguido por "Sinto vontade de fumar quando bebo" (média $=4,40 ; \mathrm{DP}=1,10$ ), com conteúdo semelhante, junto com as sentenças "Parar de fumar melhoraria minha saúde" (média =4,40; DP = 1,24), "Parar de fumar melhoraria minha respiração" (média = 4,53; DP = 1,07), e "Parar de fumar melhoraria meu desempenho nos 
esportes" (média $=4,53 ; \mathrm{DP}=1,07)$. Na Tabela 3 estão representadas as sentenças com

avaliações mais baixas realizadas pelos participantes.

Tabela 3

Crenças sobre o tabagismo com avaliações mais baixas

\begin{tabular}{|c|c|}
\hline Itens & Média (DP) \\
\hline 29. Não viajo de avião pois não posso fumar & $1,06(0,36)$ \\
\hline 28. Não viajo de avião em voos longos pois não posso fumar & $1,10(0,40)$ \\
\hline 50. Comecei a fumar para perder peso & $1,40(1,00)$ \\
\hline 26. Muitas vezes perco a linha do raciocínio pois preciso de uma pausa para fumar & $1,43(0,85)$ \\
\hline 9. Sinto vontade de fumar quando vou ao banheiro & $1,46(0,97)$ \\
\hline 24. Não consigo focar em uma atividade por muito tempo pela necessidade de fumar & $1,50(1,04)$ \\
\hline 25. Fumar costuma atrapalhar minhas atividades e compromissos & $1,50(1,04)$ \\
\hline 27. Não me sinto confortável quando em voos longos pois preciso de uma pausa para fumar & $1,63(1,24)$ \\
\hline 23. Interrompo meu trabalho para sair para fumar & $1,66(1,21)$ \\
\hline 38. Não gosto quando meus amigos param de fumar & $1,70(1,26)$ \\
\hline 39. Não apoio meus amigos a pararem de fumar & $1,83(1,31)$ \\
\hline 30. Evito ir a lugares nos quais não posso fumar & $1,90(1,24)$ \\
\hline 18. Me sinto enjoado no dia seguinte quando fumo & $1,96(1,51)$ \\
\hline 73. Parar de fumar melhoraria minha socialização & $1,90(0,99)$ \\
\hline 74. Parar de fumar promoveria minha interação com outras pessoas & $2,03(1,21)$ \\
\hline 10. Tomar café me deixa com vontade de fumar & $2,06(1,43)$ \\
\hline 35. Tenho amigos que não me apoiariam a parar de fumar & $2,13(1,47)$ \\
\hline 22. Não consigo ficar muito tempo sem fumar & $2,16(1,34)$ \\
\hline 8. Sinto vontade de fumar quando tomo café & $2,20(1,44)$ \\
\hline 13. Sinto vontade de fumar após refeições & $2,20(1,51)$ \\
\hline 36. Sinto vontade de parar de fumar quando vejo meus amigos fazendo isso & $2,23(1,43)$ \\
\hline 72. Parar de fumar melhoraria na convivência com pessoas que não fumam & $2,26(1,31)$ \\
\hline 56. Não compro meu próprio maço de cigarro & $2,30(1,60)$ \\
\hline 58. Não gosto de dividir meus cigarros & $2,30(1,48)$ \\
\hline 21. Costumo tirar pausas para fumar durante o dia & $2,33(1,62)$ \\
\hline 12. Sinto vontade de fumar após o almoço & $2,36(1,65)$ \\
\hline 41. Me sinto mal ao fumar, pois tenho outros problemas de saúde & $2,40(1,32)$ \\
\hline 47. Comecei a fumar para demonstrar que não sou mais criança & $2,40(1,45)$ \\
\hline 43. Fumar me ajuda a pensar mais claramente & $2,43(1,33)$ \\
\hline 49. Comecei a fumar para imitar as pessoas que fumam e eu admiro & $2,43(1,54)$ \\
\hline 52. Não fumo quando estou sozinho & $2,53(1,59)$ \\
\hline 6. Sinto vontade de fumar quando estou dirigindo & $2,56(1,73)$ \\
\hline 32. Evito fumar na frente de meus filhos & $2,56(1,27)$ \\
\hline 69. Parar de fumar aumentaria meu peso & $2,56(1,71)$ \\
\hline 15. Fumo quando estou esperando alguém & $2,66(1,26)$ \\
\hline 16. Fumar me mantém sempre ocupado & $2,63(1,40)$ \\
\hline 33. Fumar na frente de meus filhos me deixa decepcionado comigo mesmo & $2,66(1,18)$ \\
\hline 46. Comecei a fumar para desafiar o mundo adulto ou ambiente restritivo & $2,70(1,53)$ \\
\hline 59. Procuro reduzir a quantidade de cigarros por conta do preço & $2,73(1,59)$ \\
\hline 70. Parar de fumar mudaria a forma como as pessoas me veem & $2,76(1,67)$ \\
\hline 71. Parar de fumar aumentaria minha percepção do sabor dos alimentos & $2,80(1,60)$ \\
\hline 5. Faço novos amigos porque fumo & $2,90(1,34)$ \\
\hline 75. Parar de fumar permitiria minha permanência em ambientes sociais sem restrições & $2,90(1,64)$ \\
\hline 42. Já tentei parar de fumar mais de uma vez & $2,93(1,61)$ \\
\hline 48. Comecei a fumar para afirmar minha independência & $2,93(1,57)$ \\
\hline 79. Parar de fumar aumentaria minha ansiedade & $2,93(1,59)$ \\
\hline
\end{tabular}

Como apresentado na Tabela 3, os dois itens com menor avaliação dos participantes

são: "Não viajo de avião pois não posso fumar" (média $=1,06 ; \mathrm{DP}=0,36$ ) e "Não viajo de 
avião em voos longos pois não posso fumar" (média $=1,10 ; \mathrm{DP}=0,40)$. Também entre os itens com baixa avaliação estão "Comecei a fumar para perder peso" (média =1,40; DP = 1,00), "Muitas vezes perco a linha do raciocínio pois preciso de uma pausa para fumar" (média $=1,43 ; \mathrm{DP}=0,85)$ e "Sinto vontade de fumar quando vou ao banheiro" (média = 1,46; DP $=0,97)$. A Figura 1 ilustra as motivações dos participantes para iniciar o hábito tabagista.

É possível destacar que os participantes não consideram que o hábito impossibilita a execução de atividades, como vemos nos seguintes itens: "Não viajo de avião pois não posso fumar" (média = 1,06; DP = 0,36); "Não viajo de avião em voos longos pois não posso fumar"(média $=1,10 ; \mathrm{DP}=0,40)$; "Muitas vezes perco a linha do raciocínio pois preciso de uma pausa para fumar" (média $=1,43 ; \mathrm{DP}=0,85$ ); "Não consigo focar em uma atividade por muito tempo pela necessidade de fumar" (média $=1,50 ; \mathrm{DP}=1,04)$; "Fumar costuma atrapalhar minhas atividades e compromissos" (média =1,50; DP =1,04); "Não me sinto confortável quando em voos longos pois preciso de uma pausa para fumar" (média =1,63; DP $=1,24)$; e "Interrompo meu trabalho para sair para fumar" $($ média $=1,66 ; \mathrm{DP}=1,21)$.

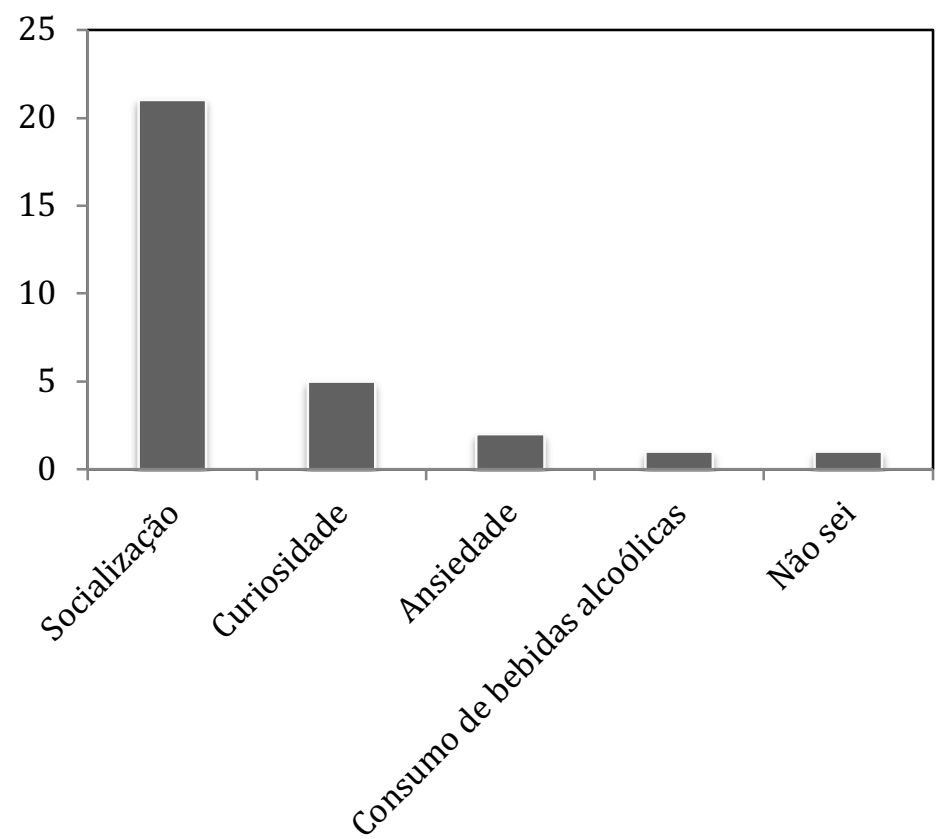

Por que razão você começou a fumar?

Figura 1. Motivação dos participantes para o início do hábito tabagista. 
É possível observar por meio da Figura 1 que 21 participantes, ou 70\% da amostra, afirmaram que iniciaram o hábito tabagista motivados pela socialização. Enquanto cinco dos participantes iniciaram pois tinham curiosidade, dois com objetivo de controlar a ansiedade, um acompanhado do consumo de bebidas alcoólicas e outro não sabe dizer sua motivação.

Por meio da pergunta "Já tentou interromper o hábito tabagista? Como foi a experiência?" foi possível destacar que 50\% dos participantes já tentaram parar de fumar mas retomaram o hábito após algum tempo, 33,33\% nunca tentaram parar e 16,66\% conseguiram diminuir a quantidade de consumo de cigarros, mas não conseguiram interromper o hábito.

Quando foram questionados se fumam em ambientes comunitários, se preocupam ou pensam se outras pessoas em volta estão incomodadas com o hábito, apenas 4 estudantes responderam que não se preocupam com as pessoas em sua volta nos ambientes comunitários, enquanto $26(86,66 \%)$ demonstraram que costumam pensar nas pessoas que estão a sua volta, pois pensam que as pessoas estão incomodadas com o hábito, se sentem julgados quando estão fumando em ambientes coletivos, pensam que o cheiro incomoda, que o hábito é prejudicial à saúde e/ ou não querem influenciar outras pessoas a fumar. 


\section{Discussão}

Por meio das análises realizas verificou-se que $66,66 \%$ dos participantes iniciaram o hábito tabagista na adolescência, entre os 14 e os 17 anos, período marcado por grandes mudanças, adaptações e experimentação de coisas novas (Almeida, 2011; Costa et al., 2017). De acordo com o que foi apresentado, o item "Comecei a fumar na adolescência" (média = $3,60 ; \mathrm{DP}=1,79)$ aparece entre os com avaliação mais alta realizada pelos participantes. Nessa fase vulnerável da vida as experiências são mais valorizadas do que hábitos relacionados à saúde (Costa et al., 2017).

Parte importante desse período de mudanças é a adaptação a novos meios sociais, como demonstram os resultados da pergunta "Por que razão você começou a fumar?", 21 dos 30 participantes, 70\%, iniciaram o hábito por meio da socialização (Almeida, 2011; Costa et al., 2017). Entre os itens dos questionários, alguns entre os que foram melhor avaliados estão também relacionados com a socialização: "Fumar ajuda na minha socialização" (média= 3,80; DP = 0,96); “Costumo dividir um maço de cigarros com meus amigos” (média = 3,60; $\mathrm{DP}=1,47)$; “Comecei a fumar para me adaptar a um ciclo social” ( média $=3,59 ; \mathrm{DP}=1,10)$; "Fumar me aproxima dos meus amigos" (média = 3,40; DP = 1,13); "Quando meus amigos param de fumar, sinto que também consigo" (média =3,36; DP = 1,51); Teria dificuldade em ver amigos fumando se parasse de fumar (média =3,30; DP =1,66); "Fumo apenas quando estou com meus amigos" (média =3,03; DP = 1,54).

Também de acordo com a relação da socialização com o hábito tabagista de jovens, entre os itens com avaliações mais baixas estão "Parar de fumar melhoraria minha socialização" (média = 1,90; DP = 0,99); "Parar de fumar melhoraria minha inteiração com outras pessoas" (média $=2.03 ; \mathrm{DP}=1,21$ ); "Sinto vontade de parar de fumar quando vejo meus amigos fazendo isso" (média $=2,23 ; \mathrm{DP}=1,43$ ); "Parar de fumar melhoraria minha convivência com pessoas que não fumam" (média = 2,26; DP =1,31); "Faço novos amigos 
porque fumo" (média = 2,90; DP =1,34); e "Parar de fumar permitiria minha permanência em ambientes sociais sem restrições" (média $=2,90 ; \mathrm{DP}=1,64)$.

Universitários aparece, como público promissor para consumo de tabaco, sendo que muitos jovens se consideram fumantes sociais por fumar apenas em bares e festas, como é o caso de 36,66\% da amostra ( Rull et al., 2011, Ministério da Saúde, 2014, citados por Guerra et al., 2017; Vargas et al., 2017; Barsosa et al., 2014). Por não se consideraram fumantes, é comum que as consequências à saúde sejam desvalorizadas. Entretanto, entre os itens com avaliação mais alta estão "Para de fumar melhoraria minha saúde" (média =4,40; DP =1,24), "Parar de fumar melhoraria minha respiração" (média =4,40; DP =1,24), "Parar de fumar melhoraria meu desempenho nos esportes" (média $=4,40 ; \mathrm{DP}=1,24)$ e "Parar de fumar aumentaria meu fôlego" (média $=4,33 ; \mathrm{DP}=1,24$ ). Por mais que os participantes tenham consciência que seus atos prejudicam sua saúde, não é o suficiente para interromper o hábito.

Também comum entre os jovens está o consumo de substâncias psicoativas, como álcool, tabaco e estimulantes. O álcool é a substância mais utilizada no mundo e muitas vezes está relacionado com o uso de outras, como alguns estudos mostram, o tabaco aparece em primeiro lugar com associação ao álcool (Almeida, 2004, 2011). Os dois itens com maior média encontrados no estudo são "Consumir bebidas alcoólicas me deixa com vontade de fumar" (média $=4,53$ 'DP = 1,07) e "Sinto vontade de fumar quando bebo" (média = 4,40; DP $=1,10)$, demonstrando a forte relação entre o consumo de álcool e de tabaco entre os universitários.

Para os universitários o tabagismo demonstra forte relação com a socialização e o consumo de bebidas alcoólicas, que aparentemente são colocados em primeiro plano que as consequências à saúde. Também foi observado que, como o hábito está associado à socialização, os participantes não percebem dificuldades em realizar atividades do dia-a-dia, como voar de avião ou trabalhar, sem fumar. 
O estudo apresentou como limitação a extensão do questionário, muitos estudantes foram resistente em participar. Além disso, sugerimos para estudos futuros acrescentar no questionário a opção de marcação "não se aplica", já que a maior parte dos estudantes não possuía filhos e marcou 1 ou 3 nas questões 32 e 33, enviesando os resultados encontrados nesses itens. 


\section{Referências}

Almeida, N. D. (2011). Uso de álcool, tabaco e drogas por jovens e adultos da cidade de Recife. Psicol. Argum., 29(66), 295-302.

Barsosa, A. de S., Barbosa, L. de S., Rodrigues, L., Oliveira, K. L. De, Iracema, I., \& Argimon, D. L. (2014). Múltiplas definições de ser fumante e diagnóstico de tabagismo : uma revisão sistemática. Aletheia 45, p.190-201, Set./Dez. 2014, 190-201.

Costa, M., Martins, M. J., Proença, A., \&amp; Silva, A. I. M. da. (2017). Crenças e atitudes de estudantes do ensino superior associadas ao uso de substâncias psicoativas.

Psychologica. https://doi.org/https://doi.org/10.14195/1647-8606 60-1_2

Guerra, F. M. R. M., Costa, C. K. F., Bertolini, S. M. M. G., Marcon, S. S., \& Parré, J. L. (2017). Consumo de tabaco entre universitários: uma revisão sistemática; Tobacco consumption among college students: a systematic review. Revista de Pesquisa: Cuidado é Fundamental Online, 9(2), 558. https://doi.org/10.9789/2175-5361.2017.v9i2.558-565

Martins, S. R., Paceli, R. B., Bussacos, M. A., Leon, F., Fernandes, A., Prado, G. F., ... Pneumologia, D. De. (2017). Medidas eficazes de controle do tabagismo : concordância entre estudantes de medicina, 43(3), 202-207. https://doi.org/10.1590

Vargas, L. S., Lucchese, R., da Silva, A. C., Guimarães, R. A., \& Vera, I., de Castro, P. A. (2017). Determinantes do consumo de tabaco por estudantes. Revista de Saúde Pública, 51, 1-9. https://doi.org/10.1590/S1518-8787.2017051006283 
Instrumento de crenças e hábitos em relação ao tabagismo

1) Por que razão você começou a fumar?

2) Já tentou interromper o hábito tabagista? Como foi a experiência?

3) Quando você fuma em ambiente comunitário, se preocupa ou chega a pensar se outras pessoas em volta estão incomodadas com o hábito? Por quê?

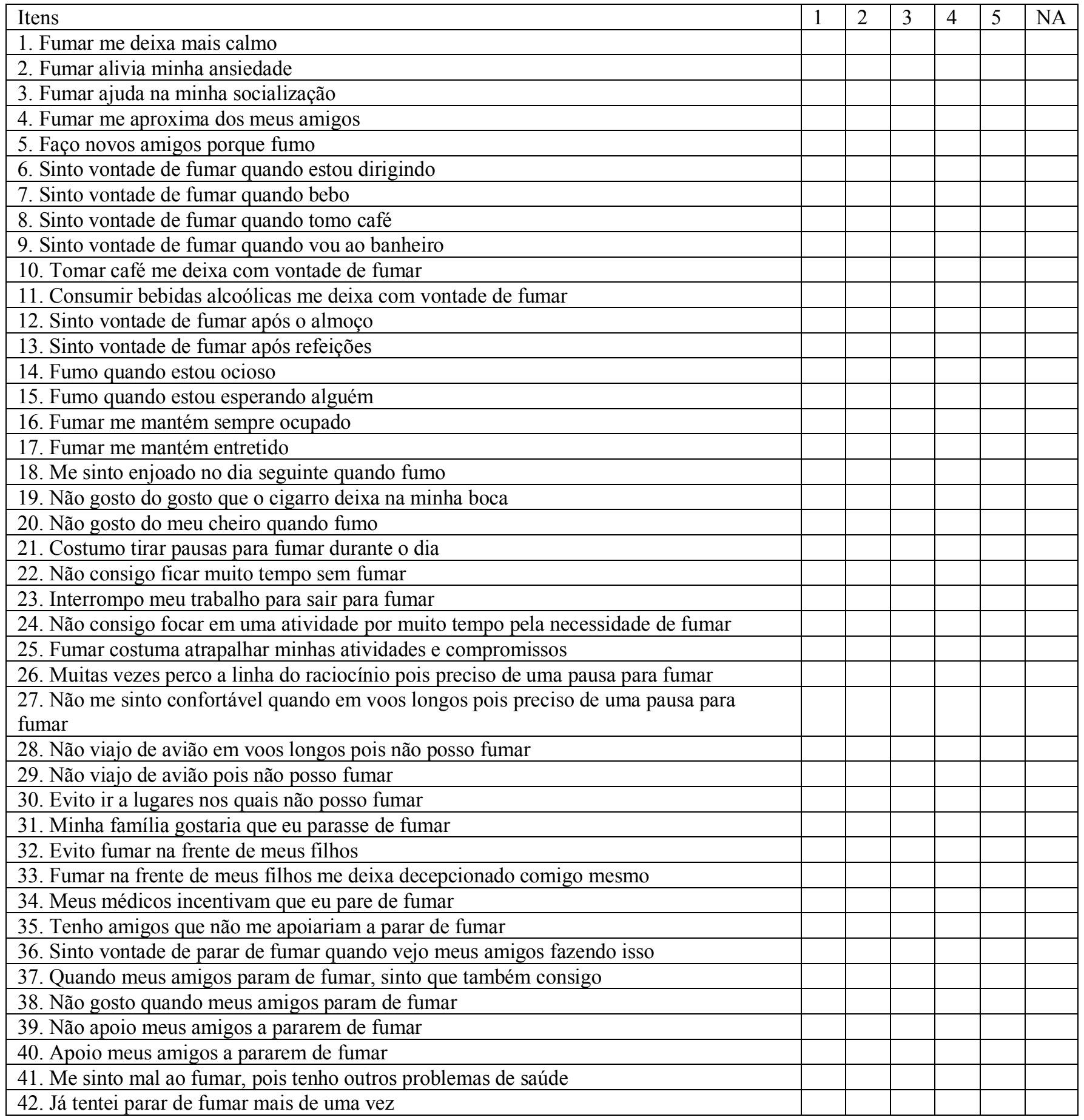


43. Fumar me ajuda a pensar mais claramente

44. Comecei a fumar na adolescência

45. Comecei a fumar para me adaptar a um ciclo social

46. Comecei a fumar para desafiar o mundo adulto ou ambiente restritivo

47. Comecei a fumar para demonstrar que não sou mais criança

48. Comecei a fumar para afirmar minha independência

49. Comecei a fumar para imitar as pessoas que fumam e eu admiro

50. Comecei a fumar para perder peso

51. Fumo apenas quando estou com meus amigos

52. Não fumo quando estou sozinho

53. Fumo quando estou sozinho

54. Costumo dividir um maço de cigarro com meus amigos

55. Costumo filar o cigarro dos meus amigos

56. Não compro meu próprio maço de cigarro

57. Eu compro meu próprio maço de cigarro

58. Não gosto de dividir meus cigarros

59. Procuro reduzir a quantidade de cigarros por conta do preço

60. Considero fumar um desperdício do meu dinheiro

61. Parar de fumar melhoraria a minha saúde

62. Parar de fumar melhoraria minha respiração

63. Parar de fumar aumentaria meu fôlego

64. Parar de fumar melhoraria meu desempenho nos esportes

65. Parar de fumar melhoraria minha situação financeira

66. Parar de fumar melhoraria meu hálito

67. Parar de fumar melhoraria meu paladar

68. Parar de fumar aumentaria meu apetite

69. Parar de fumar aumentaria meu peso

70. Parar de fumar mudaria a forma como as pessoas me veem

71. Parar de fumar aumentaria minha percepção do sabor dos alimentos

72. Parar de fumar melhoraria na convivência com pessoas que não fumam

73. Parar de fumar melhoraria minha socialização

74. Parar de fumar promoveria minha interação com outras pessoas

75. Parar de fumar permitiria minha permanência em ambientes sociais sem restrições

76. Parar de fumar melhoraria meu cheiro

77. Parar de fumar aumentaria meu stress

78. Parar de fumar aumentaria meu nervosismos

79. Parar de fumar aumentaria minha ansiedade

80. Teria dificuldade em ver amigos fumando se parasse de fumar

Itens

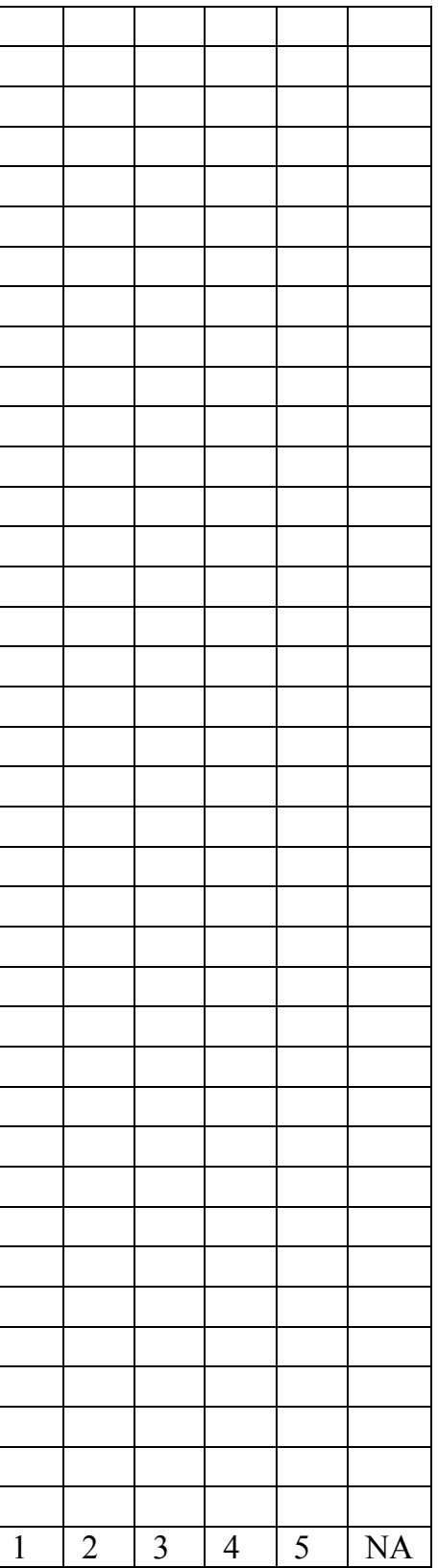

